\title{
Papers
}

\section{Opinions and practices of veterinarians and dairy farmers towards herd health management in the UK}

\section{J. Hall, W. Wapenaar}

\begin{abstract}
The objective was to compare farm veterinary surgeons' and dairy farmers' opinions on herd health plans and herd health and production management with the aim of discovering and better understanding the differences. Two comparable questionnaires, one for farm veterinarians and one for dairy farmers, were distributed throughout the UK. While listing the 'major roles' of the veterinarian on the farm, veterinarians considered 'optimising milk production', 'decreasing overall cost' and 'being an independent adviser' as important roles, but these were not seem to be perceived as such by the farmers. In addition, when presenting themselves to clients, veterinarians seemed to favour the 'friend of the farmer' approach; a much smaller proportion of farmers seemed to prefer this approach. The majority of farm respondents $(98$ of $121 ; 81$ per cent) valued the discussions with their veterinarian, and it was apparent from the relatively small proportion of veterinarians instigating a discussion on farm ( 33 of $125 ; 26$ per cent) that there is the opportunity for a more proactive approach from veterinarians. The study underlines that 'demonstrating cost-effectiveness' is still a main concern for veterinarians and farmers and identifies areas that can be improved by more training and effective communication.
\end{abstract}

\begin{abstract}
A herd health plan (HHP) is a document that describes a method intended to monitor, treat and prevent health problems and ensure the welfare of animals with the aim of being cost-effective for the farm business (Sibley 2000, 2006). The purpose is to prevent disease and improve animal health and production by introducing long-term strategies focusing on the whole herd. In the past 40 years, the balance of the veterinary profession has changed from the traditional 'healer of the sick animal' towards a 'livestock management adviser' involved in all stages of animal production and processing (Noordhuizen and others 1986, Radostits 1986). This replacement of the 'fire brigade' work from the veterinary profession by proactive herd health and production management (HH\&PM) is partly due to the increased pressure on dairy farms to become more efficient in production (Brand and others 1996). Yet, despite the move, which started in the 1970s, towards preventive proactive management, today there is modest evidence of active implementation of HH\&PM on farms (Wassell and Esslemont 1992a). HHPs are regularly seen as a mandatory requirement to be eligible to take part in assurance schemes (Bell and others 2006). Undocumented opinions undoubtedly exist with regard to the
\end{abstract}

\section{Veterinary Record (2012) 170, 441}

doi: 10.1136/vr.100318

J. Hall, BVM\&BVS, BVMedSci,

MRCVS,

St David's Farm Practice, Exmouth, Devon, EX85AN, UK

W. Wapenaar, DVM, PhD, Dip

ABVP-Dairy, MRCVS,

School of Veterinary Medicine and Science, University of Nottingham, LE12 5RD, UK reason of this limited uptake, but evidence to understand and explain the degree of implementation has not been described in the UK.

The objective of this study was to compare the opinions of farm veterinary surgeons and dairy farmers on HHPs and HH\&PM with the aim to discover and better understand differences in opinions of veterinarians and farmers on $\mathrm{HH} \& \mathrm{PM}$.

\section{Material and methods}

For the purpose of this study, HHPs were defined as 'the current paper document issued by the British Cattle Veterinary Association or other organisations'. HH\&PM was defined as 'regular scheduled farm visits that go beyond the 'one-off' tasks such as pregnancy diagnosis, castrations and dehorning. The purpose being to prevent disease and/ or improve animal health and production by introducing long-term strategies focusing on the herd as a whole?

\section{Questionnaire}

Two paper-based questionnaires, one for farm veterinarians and the other for dairy farmers, were distributed between June and September 2008. Both questionnaires comprised three sections: (1) background information, containing descriptive respondent data; (2) veterinary information, which gathered veterinarians' and farmers' opinions on veterinary services and (3) $\mathrm{HHP} / \mathrm{HH} \& \mathrm{PM}$, which gained veterinarians' and farmers' opinions on the current HHP and HH\&PM. Definitions and instructions for completion were included on the front page of the questionnaire. The questionnaire took about 20 minutes to complete. The answer format consisted predominantly of closed questions. However, if applicable, questions had the opportunity for further freetext comments if none of the provided answers applied. Questions were designed to correspond between the veterinarian and farmer versions, allowing comparisons to be made. For example, one such pairing was 'As a veterinarian on dairy farms, what do you see as your major role?' in the veterinarian questionnaire, and 'The veterinarian on my farm plays a major role in ...' in the farmer questionnaire. A pilot question- 
naire was filled in by four veterinarians and six farmers and adjusted according to their comments (full questionnaire available on request).

The questionnaire was distributed to 436 dairy farmers; 150 were disseminated by the sales team of a farming supply company, the remainder were sent to farmers across the UK identified using a telephone directory. About 300 veterinary practices were initially contacted by telephone using internet directories (www.yell.com, http:// findavet.rcvs.org.uk, www.any-uk-vet.co.uk) to request participation. Practices were chosen from the directory based on their location (county), with the aim of enrolling practices throughout the UK. When a practice confirmed to provide a service to dairy clients and agreed to participate, the number of farm animal veterinarians in that practice was requested and a corresponding number of questionnaires sent. In total, 500 questionnaires were sent to 160 veterinary practices.

\section{Data analysis}

Responses were entered in standard spreadsheet software (Excel 2003; Microsoft). Fifty per cent of the questionnaires were entered twice to identify and minimise data entry errors. When appropriate, proportions were calculated from the total number of respondents. If not all respondents answered a particular question, the total number of respondents answering the question was considered as the denominator for calculating a proportion. Multiple answers could be ticked for several questions; therefore, cumulative percentages for results reported per question could be greater than 100 per cent.

\section{Results}

\section{Veterinarian and farmer response rate}

The response rate for farmers was 29 per cent (125 of 436 farmers). One questionnaire was discarded as the respondent was a beef farmer. The veterinary questionnaire was returned by 132 veterinarians. Four questionnaires were discarded as one was from an equine veterinarian, one from a veterinarian who provided no identifier details and one veterinarian submitted the questionnaire three times. From the approximately 300 practices contacted initially, 160 practices agreed to participate; the remainder did not participate as they were exclusively companion animal practices. The response rate of the practices

TABLE 1: Distribution of farmer responses $(n=124)$ to the question: 'What is your priority for achievement on the farm? (if more than one, please rank in order of importance)

\begin{tabular}{lll} 
& Priority & Top priority \\
\hline Money/profit & 85 per cent & 56 per cent \\
Good lifestyle & 54 per cent & 11 per cent \\
Prestige & 6 per cent & 1 per cent \\
Support for future farming generation in family & 28 per cent & 7 per cent
\end{tabular}

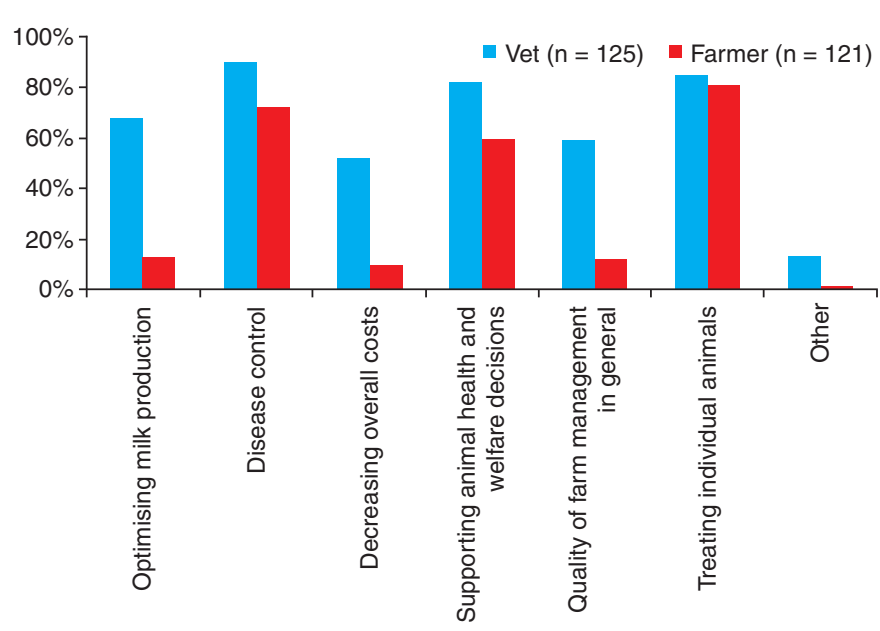

FIG 1: Frequency distribution of veterinarian and farmer responses to the question: 'As a veterinarian on dairy farms, what do you see as your major role?/The veterinarian on my farm plays a major role in...' that agreed to participate was 53 per cent ( 84 of 160 practices). The veterinarian level response rate could not be determined as the questionnaires were distributed to practices rather than individual veterinarians. In most westerly counties, both farmers and veterinarians responded, but northern counties had a predominantly veterinary response. The number of veterinarians responding from a practice ranged from one (71 per cent, 60 practices) to six (1 per cent, one practice); there were 13 practices with two veterinarians responding, five with three veterinarians, four with four veterinarians and one with five veterinarians responding.

\section{Descriptive data of the farms and farmer respondents}

Of all farmer respondents, 27 per cent $(n=34)$ were also involved in other types of farming in addition to dairying, such as beef (18 per cent, $n=22$ ), sheep ( 8 per cent, $n=10$ ), arable ( 8 per cent, $n=10$ ) or poultry ( 2 per cent, $n=2)$. The median number of lactating cattle in the respondents' herds was 120 (mean 138, range 22 to $1100, \mathrm{n}=121$ ). The median number of youngstock was 70 (mean 88 , range 0 to 400 , $\mathrm{n}=121$ ). The mean estimated milk production was 7406 litres/cow/ year (median 7500, range 4500 to $10,500, n=123$ ). The majority of respondents described their role on the farm as 'farmer owner' (82 per cent, $\mathrm{n}=102$ ) or 'owners with employed herdsman' (10 per cent, $n=12)$. Fifty-six per cent of farmers $(n=70)$ stated they had gained the major part of their farming skills from family, and 18 per cent $(n=22)$ learned their skills on agricultural courses. A combination of 'family' and 'agricultural course' was mentioned by 18 per cent $(n=22)$ of respondents. Courses were detailed by 26 respondents; 24 responses classified as 'Further Education' and two responses as 'Higher Education', according to the National Qualifications Framework (OFOUAL 2011). When asked 'What is your priority for achievement on the farm?', 'Money/Profit' was selected by 85 per cent of respondents (Table 1). 'Other' was selected by four respondents, specified as: 'enjoy a challenge' (ID117), 'good welfare' (ID91), 'providing good quality food' (ID36) and 'love the job' (ID29). When asked if they could be contacted in the future for any follow-up queries, 30 per cent (34 of 113) of respondents agreed. Eleven farmers did not answer this question.

\section{Descriptive data of the veterinary practices and veterinary respondents}

Eight practices classified themselves as a 'farm animal practice', 75 as 'mixed practice' and one practice did not answer this question. The total number of veterinarians working in the practice ranged from one to 38 (mean 8.4, median 6.0). On average, 5.4 farm animal veterinarians (median 5.0, range 0.3 to $25, \mathrm{n}=80$ ) were employed in these practices. When asked to categorise $(<10,10$ to $100,>100)$ the estimated number of dairy clients in the practice, 71 per cent (59 of 83) of the respondents' practices had ' 10 to 100 ' dairy clients.

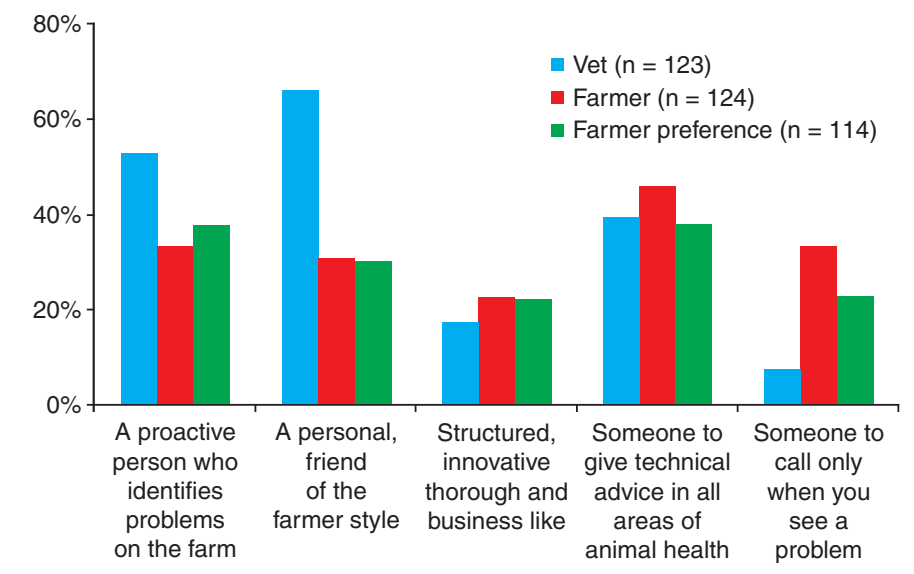

FIG 2: Frequency distribution of veterinarian and farmer responses to the question: 'How do you present yourself to your dairy clients?/What approach to you and your farm do you feel your veterinarian has?/What approach would you prefer your veterinarian to have?' 


\begin{tabular}{|c|c|c|c|c|c|c|}
\hline & \multirow[b]{2}{*}{ Yes } & \multicolumn{5}{|c|}{ Which professional? ( $\mathrm{n}=93$ veterinarians, $\mathrm{n}=38$ farmers) } \\
\hline & & Nutritionist & Al company & NMR & Consultant & Foot trimmer \\
\hline Vet $(n=125)$ & 74 per cent & 94 per cent & 30 per cent & 25 per cent & 13 per cent & 19 per cent \\
\hline Farmer ( $\mathrm{n}=123)$ & 31 per cent & 82 per cent & 18 per cent & 8 per cent & 8 per cent & 3 per cent \\
\hline
\end{tabular}

Al artificial insemination, NMR National Milk Recording

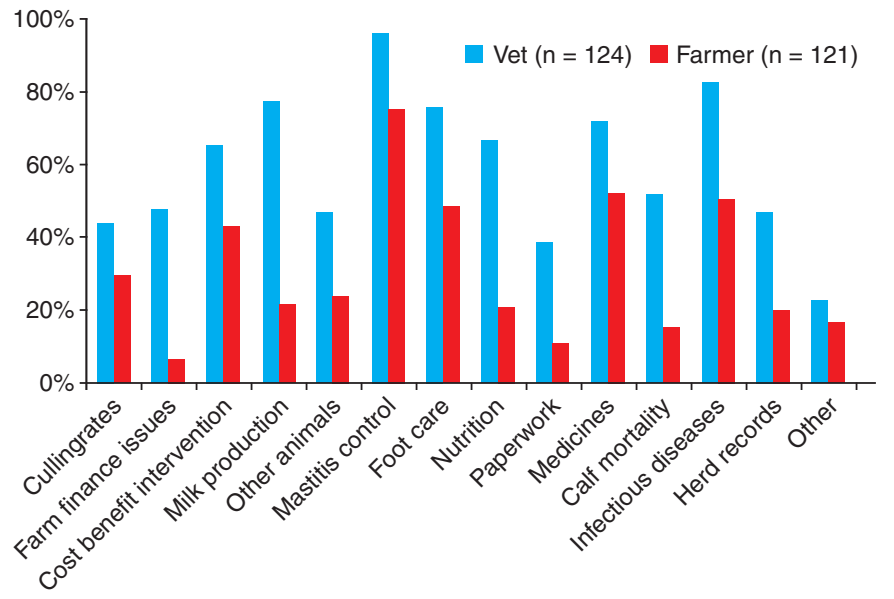

FIG 3: Frequency distribution of veterinarian and farmer responses to the question: 'During these visits to your dairy clients which topics of discussion recur?/During visits by the veterinarian, which topics of discussion recur?'

One practice response was removed from this question as veterinarians within the same practice provided different answers. The split between veterinarians with (partners, directors, principals) and without (assistants, locum, resident) a financial stake in the company was 49 per cent (60 of 122) and 51 per cent (62 of 122), respectively. There were missing data from three respondents, and three respondents' answers did not clarify their role ('vet', 'farm vet', 'vet surgeon'). When asked if veterinarians could be contacted in the future for any follow-up queries, 90 per cent (113 of 125) agreed. Three veterinarians did not answer this question.

\section{The veterinarian and veterinary visit}

When asked 'What is the major role of the veterinarian on farm?' 68 per cent of veterinarians saw their major role as 'Optimising milk production'. Thirteen per cent of farmer respondents listed this option as their veterinarian's major role (Fig 1). Fourteen per cent of veterinarians specified their major role in the 'Other' category which could be summarised as 'a trusted independent adviser who can coordinate input from other advisors'.

Three viewpoints were investigated with regard to the veterinarian's approach to the farm: the veterinarians', the farmers' and the preferred approach by the farmer (Fig 2). The most significant difference in response showed 66 per cent of veterinarians using a 'personal, friend of the farmer style', and 30 per cent of farmers preferring this approach.

Seventy-four per cent of veterinarians reported to liaise with other professionals. Most commonly mentioned professionals were nutritionists, National Milk Recording and foot trimmers (Table 2).

Both veterinarians and farmers considered 'Mastitis control' to be the most frequently recurring topic of discussion during visits, of the 14 choices available (Fig 3). Both farmers $(n=13)$ and veterinarians $(\mathrm{n}=17)$ who provided 'Other' as an answer often specified 'Fertility' as the recurring topic of discussion. Twenty-six per cent of veterinarians (33 of 125) believed they initiated the discussion on the topics as listed in Fig 3. Fifteen per cent of farmers (18 of 121) considered that it was the veterinarian who initiated discussion and 41 per cent of farmers (50 of 121) thought they instigated the discussion themselves. Twenty per cent of farmers ( 24 of 121) and 37 per cent of veterinarians (46 of 125 ) believed it was a combination of farmer and veterinarian who initiated the discussion. These discussions were perceived as valuable by 78 per cent of veterinarians ( 97 of 124) and 81 per cent of farmers (98 of 121), who both agreed that 'Discussions were good advice to put into practice'. Two veterinarians and one farmer did not value the discussion as useful and 14 veterinarians commented that the value of the discussion was often 'dependent on the client'.

\section{The HHP and HH\&PM}

When asked 'What is your opinion on the current HHP?' (options: 'No opinion', 'Useful document', 'Useless document' and 'Other, please specify'), 44 per cent of veterinarians and 44 per cent of farmers considered it a 'Useful document'. A minority of respondents, 27 per cent of veterinarians and 16 per cent of farmers, regarded the HHP as a 'Useless document'. Forty per cent of veterinarians described their opinion with detailed comments in the 'Other' category: 'Usefulness varies from farm to farm depending on attitude, but mainly useless'(ID43), 'Potentially useful but often overcomplicated and flawed' (ID102), 'Potentially useful, but ignored by farmer; initial discussion is useful' (ID105). Most of the specific comments could be summarised as 'potentially useful', 'usefulness varies per client', and 'useful if improved and updated'.

The majority of veterinarians (40 per cent; 49 of 123) considered that less than 25 per cent of their dairy clients took part in HH\&PM. Thirty per cent of veterinarians (37 of 123) estimated that more than 50 per cent of their dairy clients participated in HH\&PM.

When asked, "What are the three main advantages for farmers in participating in HH\&PM?', 40 per cent of veterinarians, compared with 27 per cent of farmers, reported that a major advantage was to improve farm economics (Fig 4). A similar difference in opinion was on 'Receiving regular and focused veterinary advice', which 23 per cent of veterinarians ranked first, in contrast to 10 per cent of farmers.

When asked "What are the major disadvantages that you see in participating in HH\&PM?' 51 per cent of veterinarians and 59 per cent of farmers stated 'Time' as the major disadvantage (Fig 5).

Eighty-two per cent of farmers (98 of 119) stated they knew enough to make an informed choice about implementation of HH\&PM on their farm. However, 32 per cent of veterinarians (39 of 122) stated their clients knew enough about HH\&PM to make an informed choice.

\section{Discussion}

Veterinarian and farmer respondents agreed that 'Disease control', 'Treating individual animals' and 'Supporting animal health and welfare decisions' were major roles of the veterinarian on the farm (Fig 1). Veterinarian and farmer respondents differed when listing other major roles of the veterinarian; although veterinarians see 'Optimising milk production', 'Decreasing overall cost' and 'Being an independent adviser' as important roles, these do not seem to be perceived as such by the farmer. The role of independent coordinator/adviser may need to be emphasised to farmers, as the majority of farmers seemed unaware that veterinarians could take on this position. Furthermore, when presenting themselves to clients, veterinarians seemed to favour the 'friend of the farmer' style approach; only a proportion of farmers seemed to prefer this approach and others 


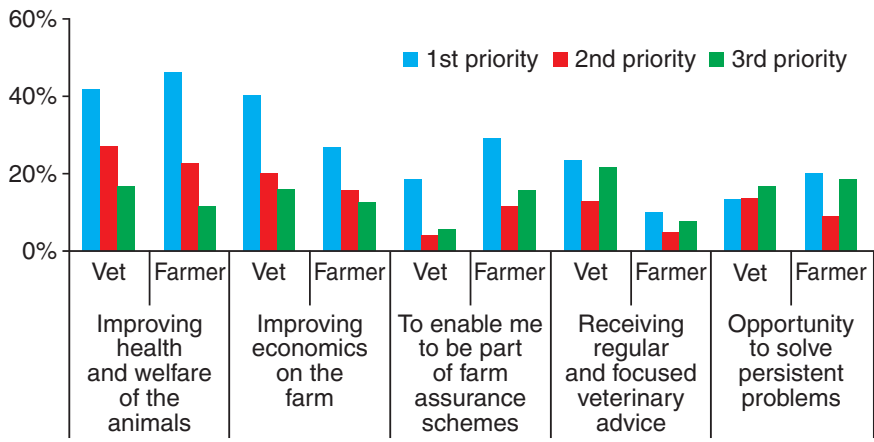

FIG 4: Frequency distribution of veterinarian and farmer responses to the question: 'What are the three main advantages that you see for the farmer in participating in Herd Health \& Production Management?/What are the three main advantages that you see in participating in Herd Health \& Production Management?' (veterinarians $=124$, farmers $=119$ )

preferred a 'proactive person who could give good technical advice' (Fig 2). Certainly, a combination of the approaches as presented in Fig 2 seems the most preferable; however, the results draw attention to the differences between farmers' preferred approaches, which is supported by a Dutch study that demonstrated certain communication strategies to be more effective in the already-motivated farmers compared with less-motivated farmers (Jansen and others 2010a).

Where veterinarians perceive to have a range of topics recurring during their farm visits, adequately representing the holistic approach of herd health management, the farmers' frequency of discussed topics was lower overall and some areas were only scarcely mentioned (Fig 3). This is supported by a similar trend observed in a Canadian study (Giger and others 1994) where veterinarians overestimated their involvement in areas such as nutrition and heifer rearing. It is possible that although veterinarians truly discuss the topics mentioned in Fig 3 , the timing and method of communication may not be effective. For example, evidence from human medicine has shown that a combination of verbal and written information can improve the standard of care of patients discharged from hospital compared with verbal instructions alone (Johnson and others 2003).

The majority of farm respondents (81 per cent) highly valued the discussions with their veterinarian, and it is apparent from the relatively small proportion of veterinarians instigating a discussion (26 per cent) that there is the opportunity for a more proactive approach from veterinarians. A proactive approach was found to be one of the most important aspects of communication with farmers, together with the fact that all persons and organisations in a farmer's social environment should articulate the same message (Lam and others 2011).

This study supports the perceived limited implementation of $\mathrm{HH} \& \mathrm{PM}$, with the majority of veterinarians indicating that less than 25 per cent of their clients participated in HH\&PM. Lack of information may be an explanation for this poor uptake, and although 82 per cent of farmers perceived to have enough knowledge to make an informed decision with regard to HH\&PM, the majority of veterinarians thought farmers did not know enough to make an informed choice. The farmer could be seen as 'unconscious incompetent', that is, they may not recognise the deficit in their knowledge. The length of time in this 'unconscious incompetent' stage depends on the strength of the stimulus the farmer has to learn, for example, how urgently animal health and production on the farm need to improve. People are often reluctant to change when the need does not seem apparent, and it is difficult to change farm management practices that are passed on through generations of farming families, particularly as the majority of farming skills were gained from family. Changing dairy farmers' attitude is difficult (Jansen and others 2010b) and, although veterinarians have a broad knowledge base, they are often not trained in communication skills. Motivating farmers to change by demonstrating increased profits may help, as 'Money/Profit' was their main priority for achievement on the farm. However, 'Lifestyle' also scored highly and 11 per cent of respondents rated 'Lifestyle' as more important

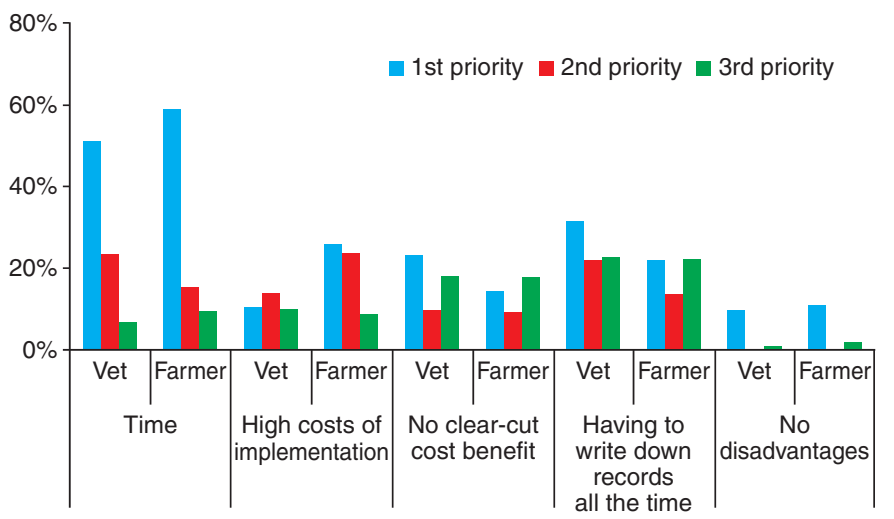

FIG 5: Frequency distribution of veterinarian and farmer responses to the question: 'What are the three major disadvantages you see in participating in Herd Health \& Production Management for the farmer?/What are the three major disadvantages that you see in participating in Herd Health \& Production Management? (veterinarians $=124$, farmers $=119$ )

than 'Money/Profit'. In a Danish study (Kristensen and Enevoldsen 2008), veterinarians appeared to focus too much on financial performance and increased production when compared with most of the participating farmers' expectations, which were described as 'teamwork' and 'animal welfare'. This suggests that finance is not always the main driver and focusing on more than cost alone is important to consider when initiating change on the farm. In previous studies, the extra cost was the principal reason for UK farmers not to join a herd health scheme (Wassell and Esslemont 1992b) and 'high cost' was also considered by Dutch farmers as the main disadvantage of HH\&PM (Lievaart and Noordhuizen 1999). It was therefore unexpected to see 'Time' ranked above finance-related issues as the main disadvantage of $\mathrm{HH} \& \mathrm{PM}$ for both veterinarians and farmers. It seems important to explore a more time-efficient application of HH\&PM, particularly in areas such as data recording, to offset this disadvantage. As well as the differences in opinion pointed out in this study, there was often good agreement among veterinary and farmer respondents. For example, when considering the advantages of HH\&PM, 'Improving health and welfare of animals' and 'Improving economics on farm' were the main advantages for both groups of respondents.

Wassell and Esslemont (1992a) reported that veterinarians considered it difficult to demonstrate cost-effectiveness of herd health schemes. The present study underlines that 'demonstrating cost-effectiveness' is still a main concern, although several cattle health schemes exist which provide information on the cost of poor health (Statham 2011). Increasing veterinary knowledge and improving veterinary training on calculating cost benefits of HH\&PM remains important to support veterinarians in practice.

A limitation of this study is the lack of knowledge whether responses are a true and accurate representation of current practice. However, as this questionnaire was anonymous and farmers and veterinarians were not selected in combination, there is no obvious reason why the respondents would not give honest answers. The independent selection of veterinarians and farmers does limit interpretation when comparing veterinarian and farmer responses; when disagreement occurs, it may reflect a true discrepancy between farmer and veterinarian, but it is also possible that this may be due to the veterinarian respondents having clients substantially different from the farmer respondents in this study and vice versa. A further study using combinations of veterinarians and farmers may clarify this. The descriptive data collected from farmers and veterinarians responding to this questionnaire displayed a varied group of respondents which are representative for their profession. Although one should be aware of its weaknesses, this study presents new information and clear tendencies that can be used to better assist farmers when implementing HH\&PM. Further studies investigating different intervention strategies are important to develop methods and approaches to successfully influence farm clients and increase implementation of HH\&PM. The veterinarian is an important stakeholder to motivate 
change on dairy farms and the results of this study identify areas that can be improved by more training and effective communication.

\section{Acknowledgements}

The authors thank all respondents who completed the questionnaire, Dr Jon Huxley and Professor Martin Green for their advice on this manuscript, and the School of Veterinary Medicine and Science for financial support.

\section{References}

BELL, N. J., MAIN, D. C. J., WHAY, H. R., KNOWLES, T. G., BELL, M. J. \& WEBSTER, A. J. F. (2006) Herd health planning: farmer's perceptions in relation to lameness and mastitis. Veterinary Record 159, 699-705

BRAND, A., NOORDHUIZEN, J. P. T. M. \& SCHUKKEN, Y. H. (1996) Herd Health and Production Management in Dairy Practice. 1st edn. Eds A. Brand, J. P. T. M. Noordhuizen, Y. H. Schukken. Wageningen Academic Publishers. pp 1-2

GIGER, R., CARRUTHERS, T. D., RIBBLE, C. S. \& TOWNSEND, H. G. (1994) A survey of veterinarian and producer perceptions of herd health services in the Saskatoon milkshed. Canadian Veterinary Journal 35, 359, 362-359, 366

JANSEN, J., RENES, R. J. \& LAM, T. J. (2010a) Evaluation of two communication strategies to improve udder health management. Journal of Dairy Science 93, 604-612

JANSEN, J., VAN SCHAIK, G., RENES, R. J. \& LAM, T. J. (2010b) The effect of a national mastitis control program on the attitudes, knowledge, and behavior of farmers in the Netherlands. Journal of Dairy Science 93, 5737-5747

JOHNSON, A., SANDFORD, J. \& TYNDALL, J. (2003) Written and verbal information versus verbal information only for patients being discharged from acute hospital settings to home. Cochrane Database of Systematic Reviews 2003, Issue 4. Art. No.: CD003716. DOI: 10.1002/14651858.CD003716
KRISTENSEN, E. \& ENEVOLDSEN, C. (2008) A mixed methods inquiry: How dairy farmers perceive the value(s) of their involvement in an intensive dairy herd health management program. Acta Veterinaria Scandinavica 50, 50

LAM, T. J., JANSEN, J., VAN DEN BORNE, B. H., RENES, R. J. \& HOGEVEEN, H. (2011) What veterinarians need to know about communication to optimise their role as advisors on udder health in dairy herds. New Zealand Veterinary Journal 59, 8-15

LIEVAART, J. J. \& NOORDHUIZEN, J. P. (1999) Veterinary assistance to dairy farms in the Netherlands: an assessment of the situation by dairy farmers. Tijdschrift Voor Diergeneeskunde 124, 734-740

NOORDHUIZEN, J. P. T. M., BUURMAN, J., WILBRINK, H. J. \& DOBBELAAR, P (1986) A computer program to support veterinary herd health and production control on dairy farms. Proceedings of the 14th World Congress on Diseases of Cattle. Dublin, August 26-29, 1986. pp 260-265

OFOUAL (2011) Explaining the National Qualifications Framework, www.ofqual.gov. uk/qualifications-assessments/89-articles/250-explaining-the-national-qualificationsframework. Accessed August 18, 2011

RADOSTITS, O. M. (1986) Bovine herd health programmes-State of the art and science. Proceedings of the 14th World Congress on Diseases of Cattle, Dublin, August 26-29, 1986. pp 233-250

SIBLEY, R. (2000) Planning Health care on dairy farms. In Practice 22, 405-406

SIBLEY, R. (2006) Developing health plans for the dairy herd. In Practice 28, 114-121

STATHAM, J. (2011) Cattle Health schemes; 2. Multifactorial or management diseases. In Practice 33, 282-285

WASSELL, T. R. \& ESSLEMONT, R. J. (1992a) Survey of the operation of dairy herd health schemes by veterinary practices in the United Kingdom. Veterinary Record 130, 260-263

WASSELL, T. R. \& ESSLEMONT, R. J. (1992b) Herd Health Schemes; their scope and use by dairy farmers. Farm Management 8, 43-49 


\section{Veterinary Opinions and practices of veterinarians and Record dairy farmers towards herd health management in the UK}

J. Hall and W. Wapenaar

Veterinary Record 2012 170: 441 originally published online March 12, 2012

doi: $10.1136 / v r .100318$

Updated information and services can be found at:

http://veterinaryrecord.bmj.com/content/170/17/441.full.html

These include:

References This article cites 12 articles, 5 of which can be accessed free at: http://veterinaryrecord.bmj.com/content/170/17/441.full.html\#ref-list-1

Article cited in:

http://veterinaryrecord.bmj.com/content/170/17/441.full.html\#related-urls

Open Access This paper is freely available online under the BMJ Journals unlocked scheme, see http://veterinaryrecord.bmj.com/info/unlocked.dtl

Email alerting Receive free email alerts when new articles cite this article. Sign up in service the box at the top right corner of the online article.

\section{Topic Articles on similar topics can be found in the following collections Collections \\ Open access (43 articles)}

Notes

To request permissions go to:

http://group.bmj.com/group/rights-licensing/permissions

To order reprints go to:

http://journals.bmj.com/cgi/reprintform

To subscribe to BMJ go to:

http://group.bmj.com/subscribe/ 